\title{
HEALTH RISKS ASSOCIATED WITH WASTE ACCUMULATION IN THE CONTEXT OF ENVIRONMENTAL LAWS
} OF DEVELOPMENT

\author{
Article history: \\ Received 16 January 2019 \\ Received in revised form 8 March 2019
}

Accepted 11 March 2019

\section{Iryna Ustinova ${ }^{1}$, Grygoryi Trakhtengerz ${ }^{2}$}

\author{
${ }^{1}$ Kyiv National University of Construction and Architecture, Kyiv, Ukraine \\ ${ }^{2}$ O.M. Marzeev Institute of Public Health of Academy of Medical Sciences \\ of Ukraine, Kyiv, Ukraine
}

\begin{abstract}
This work highlights the results of studies of environmental laws of development of urban systems that determine the cause of waste accumulation. It was disclosed that environmental pollution is an ultimative environmental factor that increases its pressure on humanity and sign of imbalance of ecological system.
\end{abstract}

KEY W ORDS - environmental laws, wastes, ash and slag wastes, landfills, environmental pollution, public health.

In ecological theory, the process of urbanization can be compared with the strategy of creating safe settlements. According to this theory, the collection in a natural city has its advantages for population such as increased viability of the group (due to cooperation) as well as disadvantages such as stress caused by overpopulation of places of residence, increased competition for environmental resources, pollution and degradation. In terms of adjacent territory, the city acts as an integral formation that absorbs materials, energy and information flows from environment and produces a large number of different types of waste. These distinctions show certain features of the metabolism of cities $[1,2,3]$.

Throughout its entire history, the humanity was focused on creation of production and consumption technologies, and only recently has become more attentive to waste management issues. Today, about 20 45 tons of raw materials are extracted per inhabitant per year. Almost $90-98 \%$ of these materials turn into waste. Accumulation of waste occurs in the domestic sector, where waste is $0.3-0.6$ tons per person [4].

"The problem of waste in Ukraine is particularly big and significant due to dominance of resourceintensive high-waste technologies in national economy of the country as well lack of an adequate response to its challenges for a long time" [5]. So according to the data of 2016, the volume of solid waste generation in Ukraine was about 11 million tons (excluding the temporarily occupied territories, the Autonomous Republic of Crimea and the city of Sevastopol). Main method for household waste management in the country remains their transportation and dumping at landfills (only $6 \%$ of generated household waste was recycled in 2016) [5].

Purpose of the study

The purpose of this study is to determine the effect of industrial and household wastes on environment and public health as well its environmental laws that determine causes of waste accumulation.

\section{Materials and methods}

Objects of the study were environmental laws that explain causes of waste accumulation as well as definite territories of Kyiv region (areas effected by ash and slag wastes generated by Trypilska heat power station (HPS) in Obukhiv district and landfills municipal solid waste (MSW) near Kryukivschina village in Kiev-Svyatoshinsky district). The choice of the designated territories was motivated by the fact that the inhabitants of the neighboring settlements, expressed their desire to defend in court their "right to a safe environment...", which is guaranteed by Article 50 of the Constitution of Ukraine. In this work, we used systemic approach, as well as methods of comparative, natural and statistical analysis.

Starting position
According to M. Reimers, waste is "...type of war materials that are unsuitable for production of this type of product, as well as their unusable residues, or substances arising during the technological processes..." [1, p. 153]. "Taking into account all types of waste, the amount of useful social product is not more than $2 \%$ of extracted natural substances and energy (the remaining 98\% are waste). Probably, it is impossible to reach better ratio since re-utilization leads to significant energy costs" [1, p. 153].

\section{RESULTS AND DISCUSSION}

Environmental laws of development.

The law of "impossibility of waste removal" states that "in any economic cycle results in accumulation 
of waste and side effects that cannot be eliminated, they can only be converted from one form to another one or replaced in space... If there was a real opportunity to get rid of waste, this would violate the laws of conservation of mass and energy. The total amount of waste in the form of matter, energy and side effects... has become practically constant: only the place of their occurrence, the time of their generation and the physico-chemical or biological form can change in production cycles... Waste removal, as only a change physico-chemical form and the movement of pollutants in space, can give a very small overall effect since it requires considerable increase in energy costs. This approach it is quite useful on local level, but it should be mentioned that it is inefficient at regional and global level, within long period of time, that the gain obtained in one place is neutralized by the loss that occurs in some other places. This problem can be solved only by reduction of pressure of society on the environment through depopulation" [1, p. 67].

The law of "development of the system at the expense of the environment", states that "any natural system can develop only through the use of material and energy as well as information capabilities of its environment. Absolutely isolated self-development is impossible. The law is based on principles of thermodynamics. It has an extremely important, theoretical and practical significance due to its main consequences: waste-free production is impossible...; any higher organized biotic system, using and modifying the living environment, poses a potential threat to more low-organized systems..." [1, pp. 70-71]. "According to the first consequence, it is only possible to count on low-waste production, therefore, the first stage of development of technologies should be their low resource intensity (both at input and output...); The second stage is the creation of cyclic production (waste generated by some enterprises may be used as raw material for others), and the third stage is the organization of a reasonable depositing (burial) of inevitable residues and the neutralization of unrecyclable energy waste (all three stages can be simultaneous)" [1, p.71]. Consequently, "the idea that the biosphere is based on waste-free principle is false, since substances that form sedimentary rock always collect and escape from the biological cycle" [1, p.71].

The law of "ecosystem self-regulation" states that the environment provides certain population capacity for each species. Population reserve, i.e. "underpopulation" of the territory, causes growth, and its exhaustion, namely overpopulation of the territory, causes the reduction in the size of the species. This is due to the fact that increase in species number results in increase in pressure on the environment and causes its resistance, which is aimed at maintaining ecological balance through depopulation. The excessive number of any species, including the species "homo sapiens", worsens the environment, which does not have time to recover and becomes less suitable for normal living of species, which leads to depopulation. In an ecologically balanced system, all waste products of the same species are removed by other. If this balance is violated, the waste is accumulated $[1,2,6]$.

\section{THE EFFECT OF INDUSTR\|AL AND HOUSEHOLD WASTE ON ENVIRONMENT AND PUBLIC HEALTH}

The purpose of works performed in State Establishment "O.M. Marzeev Institute of Public Health under Academy of Medical Sciences of Ukraine" was the determination of the effect of ash and slag waste generated by Trypilska HPS and landfills MSW near Kryukivschina village on environment and public health in Obukhiv and Kiev-Svyatoshinsky districts of Kyiv region. For this purpose, we have carried out the following studies in the areas affected by landfills of industrial and household wastes: condition of atmospheric air (with the determination of concentrations of specific pollutants); condition of soil (content of heavy metals); condition of water (in surface water bodies and water sources); morbidity of the population.

The following conditions have been disclosed at area adjacent to ash and slag disposal area excessive pollution of atmospheric air (dust with the content of silicon dioxide $20-70 \%$ to 9.2 maximum permissible concentration (MPC), chromium compounds up to $2.1 \mathrm{MPC}$ ), soil (cadmium up to $3 \mathrm{MPC}$ ), surface and ground waters and sources of decentralized water supply (cadmium up to $60 \mathrm{MPC}$, chromium up to $12 \mathrm{MPC}$, nickel up to $6 \mathrm{MPC}$, lead up to $4 \mathrm{MPC}$, manganese up to $8 \mathrm{MPC}$ in comparison with drinking water indicators). Overnormative pollution of atmospheric air within 300 meters from the ash and slag landfill (smallest allowable cross-sectional sanitary area) of remains a powerful source of dust at this territory. The air pollution with chromium compounds is just a consequence that the ash at Trypilska HPS contains these compounds. Besides in atmospheric air near Trypilska HPS small disperse dust fractions were detected. Thus, an average concentration of particles is about $10 \mathrm{mkm}(61,15 \mathrm{Mr} / \mathrm{M} 3)$ and significantly exceeds recommendations of WHO and EU.

It was also stated that excess of levels of morbidity of the population by different classes of diseases (respiratory, cardiovascular, allergic, oncological pathology); dynamics of key indicators of cardiovascular, oncological and respiratory diseases clearly correlates with the 
distance of settlements from ash and slag disposal area. Besides, in the settlements within the influence of this object there is increase in average data on oncological pathology (in 10,4 times in town Obukhov and 1,8 times in town Ukrainka), on circulatory system diseases (in 1,8 times in town Obukhov), on respiratory diseases (in 1,2 times in willlage Tripolije ).

The following conditions were disclosed at the areas adjacent to landfill near Kryukivschina village excessive pollution of atmospheric air (hydrogen sulfide 1,13 MPC, ammonia 1.15 MPC, croton aldehyde 1,2 MPC), soil (nickel 1.13 MPC, cadmium 2.52 MPC, mercury 4.9 MPC, lead 2.39 MPC, chromium 2.79 $\mathrm{MPC}$ ), ground and surface waters (nickel 5.5 MPC, cadmium $12 \mathrm{MPC}$, mercury 3.0 MPC). At the same time it was found that water pollution with cadmium, mercury and nickel in the wells of the citizens of willage Kryukovshina and in its open water basins has an unstable nature (these hazardous substances migrate in the groundwater). In our opinion a source of such pollution may be found in the MSW filtrate, which contaminates the groundwater in the surrounding territory.

Estimation of the regional morbidity among the population in the settlements near MSW revealed a tendency in a rise in number and classes of diseases closer to the landfill. Thus, closer to the landfill (village Yurijevka - 900 metres, village Kryukovshina 500 metres) cancer incidence in village Kryukovshina increased in 2,3 times; infectious disorders - almost twice; disorders of the nervous system - in 1,7 times; cardiovascular diseases - in 1,4 times.

\section{CONCLUSIONS}

1. Pollution, as one of the forms of environmental degradation, is an indicator of ecosystem imbalance. Pollution is conditioned by the accumulation of waste and acts as an increasing ultimative factor of reverse relation "population $\leftrightarrow$ environment".

2. Accumulation of wastes in the industrial and domestic sectors has negative effect on environment and public health.

3. In order to implement waste management measures, it is necessary to consider environmental laws of development.

\section{REFERENCES}

1. REIMERS N.F., 1992. Protection of nature and human environment: Dictionary. Moscow, Prosveschenie, 318 (in Russian).

2. Odum, J., 1986. Ecology: In 2 parts: translation from English, Mir: Moscow, part 2, p. 328 (+ part 1, p. 376) (in Russian).
3. Ustinova I., Trakhtengerts G., 2016. Waste problem in the aspect of violation of ecological balance and metabolism of the cities. Euro-eco-Hannover 2016. Internationaler Kongress \& Fachmesst. Hannover, EAN, 75-77.

4. BAZHeNov V.A., ISAENKo V.M., SATALKIN Y.M., 2006. Engineering Ecology: Textbook on the theory and practice of sustainable development. Kyiv, National Academy of Science, 492 (in Ukrainian).

5. Decree of the Cabinet of Ministers of Ukraine No. 820-p dated November 8, 2017 "On Approval of the National Strategy for Waste Management in Ukraine up to 2030". http://zakon.rada.gov.ua/laws/show/8202017-\%D1\%80\#n8 (in Ukrainian).

6. DoLNYK, V.R., 1992. Whether there are biological mechanisms of regulation of the number of people, Nature: № 6, p. 3-16 (in Russian). 